\title{
Fostering the Fourth Industrial Revolution Technologies for Youth and Women Empowerment
}

\author{
Elyjoy Micheni ${ }^{1}$, Alice N Wechuli ${ }^{2}$, Julius Murumba ${ }^{1 *}$, Jackson K Machii ${ }^{1}$ \\ 1. School of Business and Management Studies, the Technical University of Kenya \\ P.O Box 52428-00200, Nairobi, Kenya \\ 2, School of Computing and Informatics, Kibabii University \\ P.O Box 1699-50200, Bungoma, Kenya \\ * E-mail of the corresponding author: j.murumba@gmail.com;
}

\begin{abstract}
The fourth industrial revolution presents society with significant opportunities to incorporate emerging creative and technology innovations and strategies for youth and women empowerment. This paper uses content analysis in 1) identifying the fourth industrial revolution technologies available for youth and women's empowerment 2) exploring the capacity of 4IR technologies for empowering youth and women 3 ) investigating the difficulties faced by young and women in using these (4IR) technologies 4) exploring approaches that may encourage the use of these (4IR) innovations by young people and women. An analysis of the literature was carried out and included reports, scholarly journal articles, and conference proceedings. The keywords used were the Fourth Industrial Revolution, Youth, and women. The study concludes that the fourth industrial revolution promotes social change, improves service accessibility, improving global income levels, promoting the standard of living for youth and women, and enhancing the equitable digital economy
\end{abstract}

Keywords: Fourth Industrial Revolution; Technologies; Youth and Women Empowerment

DOI: $10.7176 / \mathrm{JIEA} / 11-1-05$

Publication date: February $28^{\text {th }} 2021$

\section{Introduction}

A UN Women's Team study (2017) found that young men and women face multiple obstacles equally due to gender discrimination stemming from unequal social conduct and practice. Many developing countries have taken steps to foster the economic and social autonomy of young people and women. These actions include improving capabilities to increase efficiency, work prospects, and leadership and increase food security (Elsayed \& Roushdy, 2017). Edralin, Tibon, and Tugas (2015) noted that women do not play a significant role in commerce, tax systems, and payment rules and regulations in their countries, though they are the backbone of economic growth in many developed countries. Documentation shows that young people and women contribute to economic growth (the Union for the Mediterranean 2017) and that empowering young people and women is critical for economic development, political stability, and social change. Empowerment is a response to people's dedication to circumstances, power, access, and understanding of their beliefs, ideals, and responsibilities that strengthen their access to opportunities and services (Edralin et al. 2015, Martínez et al. 2017)

In the work for Oxfam GB's capacity building program, Edralinet (2015) identified four phases of empowerment. These involved psychological, physical, social, and cultural practices, about which focus was recommended, for creation through different programs to help the people supported by the initiative. The Solutions for Youth Employment (2018) study indicates that in recent years, youth employment in developing countries has reached an unbearable level of youth unemployment, a sluggish transition from school to job, and increased youth isolation from mainstream economic activities. That is a significant problem because, while the number of young people and women in many of these countries is high, they face high levels of active poverty. The increased levels of unemployment reduce these groups of people's ability to develop professional skills creating barriers to their future economic empowerment. Ile \& Boadu (2018) suggest the need for education and empowerment to allow young men and women to engage in policymaking at the global, regional, and local levels. The technological achievements of several developing countries have accelerated in recent years and are strengthening the impetus for the fourth industrial revolution (Escap-Enea, 2017). Various innovations, including Big Data, IoT, and AI, forge relationships that will enable young people and women internationally to reach the fourth industrial transformation and empowerment. In this technologically led transformation of the (4IR) industrial revolution entities are 
investing increasingly in technologies and applications that allow for machines, operations, employees, and goods and services of organizations to be merged into a single data collection, data analysis, organizational growth assessment, and performance network system. The Fourth Industrial Revolution (4IR) is considered by many to be significant and global. Nagy et al. (2018) claimed that this technological transition is characterized by the blend between digital, biological, and physical realms, resulting from the growing use of new technology, such as AI, cloud computing, robots, 3D printing, the Internet of Things, etc. The Internet of Things has, among others, started an era of global disruption with unclear socio-economic implications for developed countries. Alade \& Windapo (2020) describe the Fourth Industrial Revolution (4IR) as a rapid and disruptive environmental transformation that integrates innovations that blur the connections between the physical, technical, and biological fields and therefore alter organizations' working and service delivery. In the past few years, many technological fields have seen significant progress, impacting all disciplines and economies. That includes robots, quantum computing, artificial intelligence, biotechnology, nanotechnology, internet of things, 3D printing, autonomous cars, and many more.

\subsection{The Fourth Industrial Revolution (4IR) technologies for youth and women empowerment}

The fourth technological revolution (4IR) has become the fourth major industrial period after the first industrial revolution of the 18th century, the technological revolution from the late 19th century into the early 20 th century, and the third industrial revolution that brought semiconductors, mainframe computing, personal computing, and the Internet in the 1950s. In 4IR, emerging technologies are created in an integrated way that is affecting all the physical, technological, biological fields, markets, and industries. New technological innovations are defined in all areas, habitats, and markets by the integration of the physical, technological, and biological domains. A PwC study (2017) indicates that these technological innovations allow society to change by influencing future generations in terms of economics, beliefs, personalities, and opportunities. According to the study by the UN (2019), the 4IR is driven by exponential new technologies advances such as artificial intelligence, machine learning, robotics, additives (3D), IoT, distributed DLT or block chain and quantum computing technologies and their application to biotechnology and nanotechnology. Thanks to the 4IR, innovations are being quicker, more effective, and more available than ever. Patel \& Patel (2016) refer to the Internet of Things as a network that connects everything to the web under specific objectives by using information resources to promote information sharing and collaboration to help identify, position, map, control, and handle things. IoT is a steadily growing network of web-connected computers and objects. The objects are integrated into devices that we use every day in our homes and offices. They are embedded in equipment such as handheld appliances, vehicles, and so on. They collectively perform specific tasks across different environments. The PwC (2017) study claims that IoT is a technology platform or network combining a range of innovations, such as autonomous devices, wireless sensor networks, RFIDs, microcontrollers, actuators, GPS systems, satellite technology, and internet protocols, amongst many others. The Internet of Things (IoT) has the power to give users in the developed world a wide variety of creative new services and solutions. That tackles many issues that result from high levels of poverty in these parts of the world, including governments that are willing to use the technology to expand the reach of underserved communities to basic services. In IoT, there are infinite possibilities to pursue that can offer people, businesses, and the government as a whole great deal of benefit

In Ndubuaku \& Okereafor (2015), IoT integration with big data would produce automatic information onboard. There is a need for web-based applications, that include cell phones, laptops, and vehicles equipped with sensors for gathering information such as location, status, and power usage, which the mother ship returns. With the widescale deployment of IoT, large quantities of data are generated. Owing to their size, variety, and speed, the information cannot be evaluated in the form of conventional database resources. The enormous amount of structured and unstructured data generated by IoT are mostly used in cloud services and since the data is typically heterogeneous, relational and non-relational structures like Hadoop clusters and NoSQL databases are used to explore and visualize knowledge with analytical tools. Advances in intelligence artificial capabilities have enhanced computer vision, speech recognition, robot control, language translation, online Search Engines, and social media platforms. Artificial intelligence involves developing machines capable of engaging in human-like activities such as learning, reasoning, and self-correction (Kok et al. 2011). Artificial intelligence can emulate facets of human intelligence, such as pattern detection and thought processes that reflect significant developments in automation, and are often subtly used, including the analysis of buying history and influence on marketing decisions. AI varies from software that can think about looking for algorithms used in board games to apps that people use computers in the business in virtually all realms. Grewal (2014) claims that AI's not about robotics but rather an understanding of the essence of smart thinking and action using machines as testing instruments and that AI robots are becoming increasingly effective platforms to test ideas of intelligent behavior worldwide. Robots are available for industrial purposes and are now used globally in industrial factories. But robotics is not limited to production, with recent advances, including support robots for people who have vision issues, low-cost robots 
for the food industry, and autonomous robots for the structural maintenance of nuclear power plants and underground mines. Robots are autonomous motorized tools that can transform our lives by preparing food, playing music, filming our shows, and even driving our cars. When specially designed, robots are capable of creating new jobs. They can also increase the quality of current ones, and people no longer need to specialize in what they want to do (Xu, David, \& Kim, 2018). Block chains and associated developments in technology also have the potential to challenge socio-economic processes. According to UNIDO (2019), recent technological advancements in the financial sectors indicate a possibility of moving social trust from government-backed organizations to structures with explicitly defined codified inputs. These include records, properties, and the valuation of goods and services. Block chains can build partnerships and processes by using intelligent contracts that allow timely performance and productivity, minimize errors, and even challenge the position of markets and governments. Block chains can contribute to the automation of planning and property creation in conjunction with AI technologies. A good example of this is the land registry office in Brazil which has piloted the Block chains project to boost the reliable ownership of records (PwC, 2017).

Additive manufacturing (AM), innovative and increasingly common technology in the manufacturing industry, embodies the innovative advancement of the trendy manufacturing industry and represents a phase through which an entity is created directly from 3D model data by joining content, layer by layer. AM provides a strategic edge over conventional production technology through the cost-effective and time-effective manufacture of volumes, personalized goods with complex geometries, and material properties (Saadia et al. 2019). Additive manufacturing can be a promising, digital alternative to an industrial concept that has gained widespread attention all over the globe as opposed to conventional subtractive manufacturing technologies by creating object-by-layer (3D) CAD models in three dimensions. AM offers various advantages: 1) It produces goods with complex forms, such as topologically optimized structures which are difficult to render with conventional casting or forging processes; 2) AM is also used to produce new material characteristics, such as dislocation networks; and 3) It reduces material waste and thus saves on cost for industry (Qi, Chen, Li, Cheng, \& Li, 2019). Quantum computers (QCs) offer an alternative computational method that may vary qualitatively from previous computing methods. Quantum computers are ideal for future computers .e.g. function minimization. They are written in abstract and highly general terms and are capable of solving problems with a time that develops more slowly compared to the input volume (Emani et al. 2019. Machine Learning (ML) is a reliable method for complex pattern recognition and regression analysis. It has been demonstrated without the particular requirement of designing and overcoming the underlying physical models. The neural network (NN) is the most commonly used model of ML algorithms since its massive data sets, powerful computing power, and advanced algorithm design are currently usable (Qi, Chen, $\mathrm{Li}$, Cheng, \& Li, 2019). Synthetic biology is an interdisciplinary division of the biology industry that is a solid 4IR technology in the area of biological mega-trends, incorporating the concepts of engineering in the biological environment. Considerable progress has been achieved in reducing the value and increasing the convenience of genetic sequencing and lately inactivating or editing genes. Synthetic biology offers us the capacity for writing DNA to fit organisms. United Nations Industrial Development Organization (2019) estimates those genomic, nanamedical, customized drugs, 3D imaging, and human organ development and transplantation breakthroughs aim to expand life spans and transform human well-being.

\section{The Potential of 4IR technologies for youth and women empowerment}

The Fourth Industrial Revolution could boost global incomes and raise living standards for the world's population. Schwab (2016) argues that technology has made it possible for us to create new products and services which better our personal lives, while the customers who are ready for digital access and productivity will be the ones who benefit the most from them. For example, to make a payment for a product or service, book a flight, order a taxi, watch a movie, or play a game from anywhere in the world, as the technical advancements in technology like AI, IoT, and Big Data analytics are experiencing disruptive changes. As a collaborative culture, the fourth industrial revolution in many business groups led to computers being linked, involving the use of sophisticated predictive software, systematically translating data into knowledge essential for clarifying uncertainties, and making educated decisions (Nagy, Olah, Erdei, Máté \& Popp, 2018). The fourth industrial revolution is not only a technical transition but is driven by a revolutionary breakthrough and is having a positive effect on our key industries such as education, healthcare, and business (Xu, David, \& Kim, 2018).

To reach their transformative potential, technical developments in the 4IR must be rooted in concrete social and political transformations that are anchored in modern economic, social, and political arrangements. These emerging innovations will offer public services to address many obstacles to technology penetration that youth and women face, such as distances and limitations enforced by communities or families, according to Cummings 
\& O'Neil (2015). With awareness and the use of new and evolving digital technology, young people and women can effectively develop their confidence, expand their economic strength and freedom, make better-informed choices, connect to online collaborators, share information and build unity, and inspire policymakers to resolve problems that concern them. The increased connectivity of people and the availability of expertise contribute to endless opportunities powered by emergent AI, quantum computing technologies, robotics, biotechnology, process automation and 3D printing. That could displace several jobs in low- and middle-skilled jobs. The fourth industrial revolution will increase income by encouraging entrepreneurs to pursue innovations and to raise the living standards of young people and women worldwide. For technical developments in the 4IR to reach their transformative potential, they must be rooted in concrete social and political transitions rooted in modern economic, social, and political arrangements. These emerging innovations may offer public services that address many technical obstacles that young people and women face. Such may include the physical distance or constraints that communities or families impose on them (Cummings \& O'Neil, 2015). The youth and women can effectively develop their self-confidence, economic strength, and freedom through using modern and evolving digital technology. They can also make more informed decisions, discuss online with friends, share knowledge, create unity, and lobby decision-makers about their concerns.

The increased human connectivity and access to information have given rise to endless opportunities driven by emerging technologies. These cover AI, robotics, process engineering, $3 \mathrm{D}$ printing, biotech, and quantum computing, which can displace multiple workplaces in low and medium-skill jobs. The Fourth Industrial Revolution would increase income by encouraging businesses to follow their new ideas and boost youth and women's living standards worldwide. The rapidly expanding use of technologies in the industry like robotics, process automation, and big data to make smarter supply chains, and AI for decision-making is heralding technological innovations. In turn, these are helping redefine the work environment, creating a new economy of gig-based independent contractors who are reshaping when and where work is completed and blurring the definitions of formal and informal employment (Brown, Lloyd, \& Souto-Otero, 2018) (Brown, Lloyd, \& SoutoOtero, 2018). Xu, David \& Kim (2018) note that technical advances can be a blessing on the supply side, with long-term performance and productivity improvements. Transportation and communication costs are likely to drop; logistics and global supply chains will become simpler. Therefore the cost of trade will diminish, all of which can open new markets and drive the economic process. 4IR technology provides an incentive for developed countries to break through conventional phases of economic growth. For example, cell phones have already minimized countries' need to get costly fixed lines. Online and mobile banking also eliminate the need for physical banking branch networks. 4IR would also motivate SMEs, which are the bedrock of many developed countries' economies and are possibly an important source of innovation (Menon \& Fink, 2019)

\section{Challenges of adopting fourth industrial revolution technologies by youth and women}

The fourth industrial revolution would undoubtedly have far-reaching effects on almost every aspect of lifestyle, including how people communicate with technology. This accelerated growth is noticeable to and available by others as a product of the digital divide, according to the Global Business Coalition for Education (2008). 4IR effects vary across countries and cultures, requiring diverse ways to tackle automation and digital technology issues. This disparity causes young entrepreneurs problems, and maybe the potential workforce will not be well prepared for 4IR or even be conscious that we are facing a revolution. In an era driven by emerging technology, the scarcest and most valuable resources would not be ordinary labor or ordinary money, but rather the individuals who will generate new ideas and new inventions. In the future, creativity and money will be the critical element in development, where individuals with ideas, not staff or buyers, would be the least available. The quest for talent has become an important factor in the job market and turn will be more and more segregated. Under the ongoing technological revolution, the labor market is under threat of massive labor displacement (Xu, David, \& Kim, 2018). 4IR technology can displace lower-skilled employees while complementing higher-skilled employees, which mean more low-skilled manufacturing routine jobs, in which Africa features on, will be substantially automated. That will make many jobs that could be done by youth and women in developing countries to be replaced by technology (Naudé, 2017). Emerging innovations in some industries would not only reduce employment but also further intensify gender inequality. Automation is therefore putting youth and women's work in productive sectors arising from the 4IR in difficulty since they are found mostly in low skill and repetitive occupations. Naudé (2017) states that it's unlikely that most young people and women will benefit from technology growth because they don't have the competence they need in the evolving information economy. There are expectations of many other problems in the 4IR, including cyber - attacks and hacking. There is a significant increase in possible disruption and interruption as a result of cyber attacks. The vulnerability to cyber attacks is likely to increase as we are connected widely with a wide range of computers, sensors, and web-based machines. Xu, David \& Kim (2018) suggest that the fourth industrial revolution requires more cyber security because it monumentally raises the flaws of a network 
having all connected to something else inside IoT. That is attributed to a need for higher standards of creating alerts and for devices to stay safer as more gadgets like mobile phones, vehicles, light-weight switches, home surveillance cameras, and smart speakers are connected. The dramatic developments that take place in all sectors make leadership and opportunities in 4IR hard to manage when they re-form the social system by implementing modern business models. Leadership has a role to play in making every organization competitive in virtually every change initiative and is the ultimate secret to the success of organizations that carry the change initiative through everyday business operations (Alade \& Windapo, 2020). Alade \& Windapo (2020) also notes that leaders are obviously in a position to manage change innovation and resolve the pressures of technical transformation and they need a special leadership style to support the fourth industrial revolution and hence the digital age. Employment in many industries is evolving and fragmenting, contributing to work trends that pose problems for young people and women. Popular innovations like Uber have arisen, impacting traditional firms in the taxi sector, whilst Airbnb is now more successful than many other global hotel groups. There is a chance for a significant portion of the gains gained in maintaining access for young people and women in jobs e.g. paid maternity leave, to vanish as employment becomes more fragmented with competition to every new job. Chiweshe (2019) argues that patriarchal values, traditions, and practices generally preclude women from owning, in particular, land. Youth and women are in unskilled occupations in the lower echelons of the economy in many developing countries. These are mainly in agriculture in these countries, such as Kenya, Ethiopia, Malawi, Niger, Tanzania, etc. The fourth industrial revolution has directly affected these places by increased automation (Chiweshe, 2019). Another critical challenge is uncertainty over the high costs of the latest technologies. Combes et al. (2017) argued that, due to their perceived high costs, the private sector will probably take risks of investing in these frontier technologies, a scenario which can lead to an exponential growth of these technologies, but which will extend the technological gap which marginalizes young people and women. In developing countries, the penetration of 4IR technology is much lower than in developed countries. If the developed world does not have the infrastructure at the optimized cost, it is not feasible for these countries to follow the governance and business models expected by 4IR (Combes et al. 2017)

\section{Strategies for use of 4IR technologies by Youth and Women}

The 4IR marks the transition from simple digitalization by a convergence of modern technology and networks in the third technological revolution to revolutionary innovation. The way businesses work in the engineering, logistics, and agricultural industries are evolving with 4IR technology. Gastrow (2020) says that building capability will be a precondition for global competitiveness and the use of technology to meet the 4IR goals of human development. Distinctive areas of focus include (1) education, (2) research, development, and innovation (RDI), and (3) creativity in the public sector. It is necessary to eliminate barriers and expand access to new technology and avenues for young people and women's social and political participation. That is because the planning paradigms have emerged to be consistent with sustainable development goal number five. The achievement of equality between men and women is a prerequisite for making progress on the UN's 2030 agenda for sustainable development. Within the context of these objectives, the world leaders have committed to achieving full, effective, and decent work for all, including for youth and disabled people (SDG 8) and gender equality and empowerment for all women and girls (SDG 5). Alade \& Windapo (2020) report shows that several leadership types are documented in the literature, which classifies leaders as autocratic, democratic, transactional, transformative, charismatic, and strategic. The change leadership style (Trautlein \& Trowbridge, 2013; Dulewicz \& Higgs, 2004) is the most appealing. It shows that leaders differ in their attitude towards efficiency in different circumstances when a leader acts as trainer, advocate, visionary, guide, executor, facilitator, or adapter for organizational change. Each leader is distinguished by a unique style of leadership, and by how powerful the leader is at the bottom (people-oriented), at the head (purpose-oriented), or the hands of the leader (process-oriented). It is thought that the leaders would drive the 4IR by integrating such functions.

Some organizations have begun campaigns to transform youth and women's mindsets. For example, PepsiCo and 21 Century Fox have launched a multi-platform integrated campaign targeted at girls 13-19 years of age and over 20 to inspire more women to think about their careers in science, technology, engineering, and Mathematics. Studies have shown that the potential for overall economic growth and advancement increases if communities train girls of younger age in science, technology, engineering, and mathematics (STEM) and prepare them for workforce jobs. In Africa, governments and the African private sector are urged to introduce and expand existing STEM youth-focused programs. Globally, programs by companies and agencies such as Google, Amazon, the United States National Aeronautical and Space Administration, and various universities are exemplary. These are models for young women to engage in STEM that can be adopted by African and other developed states (World Economic Forum, 2017). Chiweshe (2019) supports projects like the South African Cape Town Code that focus on improving women's participation and economic empowerment. Support is given through engendering technology, 
engendering development, engendering knowledge networks, engendering business, engendering management, engendering energy, engendering the workplace, engendering AI, and engendering leadership. Besides issues that make holistic contributions to women's empowerment, which range from professional or private life to entertainment and information and consumer power, the generation of technology, according to Kamberidou \& Pascall (2020), covers employment, and thus the financial empowerment of women. In some ways, the 4IR revolution may fail women, especially in Africa, without a concerted effort to engage in socially inclusive processes. It is necessary, therefore, to know not only the problems women face but also the enormous opportunities technological advances bring (Chiweshe, 2019) Access to technology is hindered by the absence of earlier industrial revolutions by large parts of developing countries, particularly Africa. Limited investment has been made in infrastructures such as roads and electric networks to make technology available, including the internet. That has created a digital divide that governments must fix to realize the benefits of the 4IR. While critics contend that exponential technology is broadening the gap between rich and poor, the technology is neutral. The question is how to use that technology. For many countries to have a vibrant and inclusive economy, affordable and equal access to devices, services, and ICTs is required. Technology and content must be made available to all, living conditions and social growth need to be improved, and adequate data governance such as user security. All these are requirements for a fair digital economy to be guaranteed (Digital Future Society, 2019).

Moreover, to achieve transformative empowerment for young people and women, the National Youth Empowerment Strategy (2015) noted that it was important that the government emphasizes the following areas in the interests of the 4IR. 1) Policy and Legal Framework: Government policies and legislative mechanisms that address concerns of youth and women on all levels need development; meaningful representation and justice for women and young people. Regulate innovations in compliance with privacy, security, and freedom of expression; break down strategic alliance barriers. Policies also include creating a sustainable climate, legislative, and policy and programs that facilitate the fair access of women to ICT 2) Leadership and Participation: In most developing countries, young people have been marginalized in terms of conventional politics, culture, and economics. In terms of youth and women's participation, democratic structures, political growth, and political institutions are seen as limited. Governments and stakeholders need to formulate strategies to foster inclusiveness, participatory and interactive policies through youth engagement in supporting women's lobbying, advocacy, and free decisionmaking on all systemic and growth concerns at all levels of governance 3) Employment and Skills Development: There is a need to create a framework for a favorable climate that promotes entrepreneurship, training, and job development, as well as sustainable labor demand and supply balance. The support of work centers and labor market information systems must respond to the skills gap between graduates and industry. This aspect also deals with promoting job prospects for young people in the IT sector 4) Innovation, Creativity, Technology, and Talent Identification \& Development: UNDP (2017) reports that youth do not benefit from development efforts. In resolving everyday problems women and youth must engage in the production and distribution of ICT and 4IR technologies by government agencies. Chances for young people and women are considered drivers of change in tackling their life struggles positively if the three-goal strategy is applied. UNDP (2017) states the strategy as "working for youth as beneficiaries; engaging with youth as partners/collaborators; and supporting youth and women as leaders /initiators". It is, therefore important to build structures to identify, grow and promote creativity, skills, and talents by creating forums, encouraging, managing, and protecting youth creativity, innovations, and talent. Equally important is the provision of internships, job opportunities, training or workshops, and voluntary programs to help young people and women step into the labor market and match their skills. Development of resources and methods with industry partners to take a gender-responsive approach to innovation is required. Investment is needed in innovations that respond to the needs of youth and women, as well as promoting and empowering start-ups and financial support for them as innovators and entrepreneurs. 5) Agriculture, Environmental Management, and Sustainable Development: The Government must provide a good environment, assistance, and mechanism for young people and women engaged in agriculture, conservation, eco-enterprises or green jobs, green processes, and 4IR technologies. That includes empowering rural women farmers through mobile and 4IR technology. To develop an innovation market that promotes gender equality and empowerment of women and girls, it is also important to build market awareness through investments and industry-wide measures. 6) Health, Crime, Drug, and Substance Abuse: Adequate initiatives and youth-friendly health facilities must be created and funded to minimize HIV/AIDS, drug and alcohol misuse, and the health concerns of young people and women. 


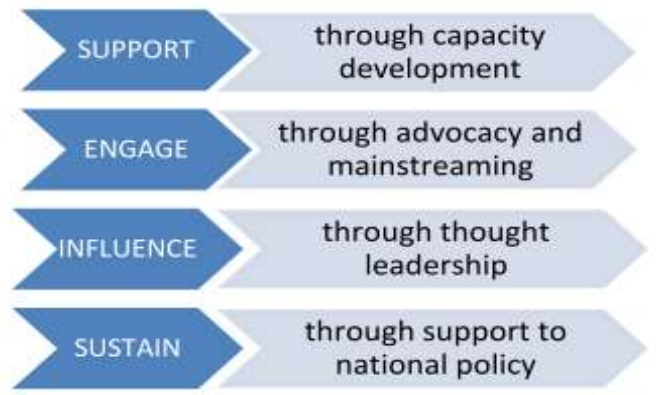

Figure1: Four-Pronged Approach to Empower Youths (Adapted from UNDP, 2017)

\section{Conclusions and Recommendation}

This study has discussed the Fourth Industrial Revolution (4IR) technologies that are useful in youth and women empowerment, the potential offered by these technologies, the challenges of adopting these technologies by youth and women, and the strategies that can be used for successful adoption. The study concludes that the fourth industrial revolution is facilitating the societal shifts; increased accessibility of services; improve the global income levels; promote the standard of living for youth and women and enhanced equitable digital economy. The study recommends that for a vibrant and inclusive economy the developing countries need to provide appropriate policy and legal framework; leadership; innovation support and equitable access of ICTs by youths and women.

\section{References}

1. Alade, K., \& Windapo, A. (2020). 4IR Leadership Effectiveness and Practical Implications for Construction Business Organisations. In C. Aigbavboa, \& W. Thwala, The Construction Industry in the Fourth Industrial Revolution (Eds ed., pp. 62-70). Cham: Springer.

2. Brown, P., Lloyd, C., \& Souto-Otero, M. (2018). The Prospects for Skills and Employment in an Age of Digital Disruption: A Cautionary Note. Oxford: SKOPE Publications.

3. Chiweshe, M. K. (2019). Fourth Industrial Revolution: What's in it for African Women? Centre for International Governance Innovation (CIGI).

4. Combes, B., Nassiry, D., Fitzgerald, E., \& Moussa, T. (2017). Emerging and Exponential Technologies: New Opportunities for Low-Carbon Development. London: CDKN.

5. Cummings, C., \& O'Neil, T. (2015). Do digital information and communications technologies increase the voice and influence of women and girls? London: Overseas Development Institute.

6. Digital Future Society. (2019). Bridging digital divides: A framework for digital cooperation. Barcelona, Spain.

7. Dulewicz, V., \& Higgs, M. (2004). Assessing leadership styles and organisational context. Journal of Managerial Psychology, 20 (2), 105-123.

8. Edralin, D. M., Tibon, M. V., \& Tugas, F. C. (2015). Initiating Women Empowerment and Youth Development through Involvement in Non-Formal Education in Three Selected Parishes: An Action Research on Poverty Alleviation. DLSU Business \& Economics Review , 24 (2), 108-123.

9. Elsayed, A., \& Roushdy, R. (2017). Empowering young women through Business and Vocational Training: Evidence from a field intervention in rural Egypt. Geneva: Labour Office.

10. Emani, P., Warrell, J., Anticevic, A., Bekiranov, S., Gandal, M., McConnell, M., et al. (2019). Quantum Computing at the Frontiers of Biological Sciences. arXiv: Quantum Physics.

11. ESCAP ENEA. (2017). Innovative Big Data Approaches for Capturing and Analyzing Data to Monitor and Achieve the SDGs. Incheon.

12. Gastrow, M. (2020). Policy options for the Fourth Industrial Revolution in South Africa. Human Sciences Research Council.

13. Grewal, D. S. (2014). A Critical Conceptual Analysis of Definitions of Artificial Intelligence as Applicable to Computer Engineering. IOSR Journal of Computer Engineering (IOSR-JCE) , 16 (2), 09-13.

14. Ile, I., \& Boadu, E. S. (2018). The paradox of youth empowerment: Exploring youth intervention programme in Ghana. Cogent Social Sciences , 4 (1).

15. Kamberidou, I., \& Pascall, N. (2020). The Digital Skills Crisis: Engendering Technology-Empowering Women In Cyberspace. European Journal of Social Sciences Studies , 4 (6).

16. Kok, J. N., Boers, E. J., Kosters, W. A., van der Putten, P., \& Poel, M. (2011). Artificial Intelligence: Definitions, Trends, Techniques, and Cases. Encyclopedia of Life Support Systems.

17. Martínez, X. Ú., Jiménez-Morales, M., Masó, P. S., \& Bernet, J. T. (2017). Exploring the conceptualization and research of empowerment in the field of youth. International Journal of Adolescence and Youth . 
18. Menon, J., \& Fink, A. (2019). The Fourth Industrial Revolution and Its Implications for Regional Economic Integration in ASEAN. Journal of Asian Economic Integration , 1 (1), 32-47.

19. Nagy, J., Oláh, J., Erdei, E., Máté, D., \& Popp, J. (2018). The Role and Impact of Industry 4.0 and the Internet of Things on the Business Strategy of the Value Chain-The Case of Hungary. Sustainability

20. National Youth Empowerment Strategy. (2015). A flagship project of Vision 2030 Medium Term Plan II 2015-2017 (Issue May 2015).

21. Naudé, W. (2017). Entrepreneurship, Education and the Fourth Industrial Revolution in Africa. Bonn: IZAInstitute of Labor Economics.

22. Ndubuaku, M., \& Okereafor, D. (2015). Internet of Things for Africa: Challenges and Opportunities. International Conference On Cyberspace Governance - Cyberan2015, (pp. 23-31). ABUJA.

23. Patel, K. K., \& Patel, S. M. (2016). Internet of Things-IOT: Definition, Characteristics, Architecture, Enabling Technologies, Application \& Future Challenges. International Journal of Engineering Science and Computing , 6 (5), 6122- 6131 .

24. PwC. (2017). Harnessing the 4th Industrial Revolution for Sustainable Emerging Cities.

25. Qi, X., Chen, G., Li, Y., Cheng, X., \& Li, C. (2019). Applying Neural-Network-Based Machine Learning to Additive Manufacturing: Current Applications, Challenges, and Future Perspectives. Engineering , 721-729.

26. Saadia Razvi, S., Feng, S., Narayanan, A., Tina Lee, Y.-T., \& Witherell, P. (2019). A Review Of Machine Learning Applications In Additive Manufacturing. International Design Engineering Technical Conferences and Computers and Information in Engineering Conference. Anaheim, CA, USA: ASME.

27. Schwab, K. (2016). The Fourth Industrial Revolution: what it means, how to respond. Retrieved October 1st, 2020, from World Economic Forum: https://www.weforum.org/agenda/2016/01/the-fourth-industrialrevolution-what-it-means-and-how-to-respond/

28. Solutions for Youth Employment. (2018). Digital Jobs for Youth: Young Women in the Digital Economy. Washington, DC: The World Bank.

29. The Global Business Coalition for Education. (2018). Preparing tomorrow's workforce for the Fourth Industrial Revolution For business: A framework for action.

30. the Youth Team of UN Women. (2017). Un Women's Youth And Gender Equality Strategy: Empowered Young Women And Young Men As Partners In Achieving Gender Equality. UN Women.

31. Trautlein, B. A., \& Trowbridge, C. (2013). You know your IQ, but what's your CQ? develop your change intelligence to lead successful and sustainable transformation and results. PMI Global Congress North America. New Orleans, LA. Newtown Square: Project Management Institute .

32. Union for the Mediterranean. (2017). Visions and actions to promote gender equality in the Mediterranean. Barcelona: ufm secretariat.

33. UNDP. (2017). UNDP Youth Strategy 2014-2017. Empowered Youth, Sustainable Future. March 2014.

34. United Nations Industrial Development Organization. (2019). Bracing for the New Industrial Revolution: Elements of a Strategic Response. Viena.

35. World Economic Forum. (2017). Accelerating Gender Parity in the Fourth Industrial Revolution An Agenda for Leaders to Shape the Future of Education, Gender and Work. White Paper, Geneva.

36. Xu, M., David, J. M., \& Kim, S. H. (2018). The Fourth Industrial Revolution: Opportunities and Challenges. International Journal of Financial Research , 9 (2), 90-95. 